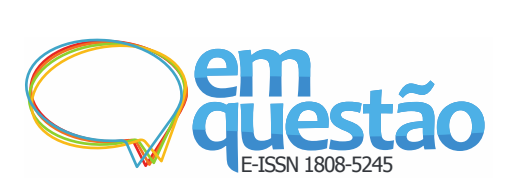

\title{
As bibliotecas universitárias e os desafios da pós-modernidade
}

\author{
Liliane Vieira Pinheiro \\ Doutora; Universidade Federal de Santa Catarina, Florianópolis, SC, Brasil; \\ liliane.pinheiro@ufsc.br \\ Ligia Maria Arruda Café \\ Doutora; Universidade Federal de Santa Catarina, Florianópolis, SC, Brasil; \\ ligia.cafe@ufsc.br \\ Edna Lúcia da Silva \\ Doutora; Universidade Federal de Santa Catarina, Florianópolis, SC, Brasil; \\ edna.1.s@ufsc.br
}

\begin{abstract}
Resumo: O ensaio traz reflexões sobre as bibliotecas universitárias e os desafios enfrentados na atualidade. Tem por objetivo levantar possíveis funções e papéis dessas instituições no cenário denominado de pós-modernidade. Discorre sobre a pós-modernidade e os desafios educacionais relacionados às universidades e, em decorrência, às bibliotecas universitárias. Mostra os significados das bibliotecas e o lugar delas na história da humanidade. Considera que para dar conta dos desafios postos pela pós-modernidade, as bibliotecas universitárias têm de apostar na pluralidade seja quanto às abordagens, aos tipos e à idade dos materiais incorporados as suas coleções, seja quanto a oferecer apoio ao ensino, à pesquisa e à extensão tanto quanto ao aprendizado autônomo. Além de ser um lugar de preservação da memória científica da humanidade.
\end{abstract}

Palavras-chave: Bibliotecas universitárias. Pós-modernidade. Memória científica.

\section{Introdução}

Vive-se em tempos de mudanças rápidas e intensas e de novos cenários no campo do saber. O modelo clássico de pensar o mundo apoiado no paradigma cartesiano e na lógica quantitativa, causal e linear não dá mais conta de explicar ou entender a realidade.

Santos (1994) identificou essa crise paradigmática, classificando-a como sem precedentes, pois difere de todas as anteriores. Segundo o autor, para além da crise de transição modelar, há certamente outra insinuada, que é a crise 
societal. O novo e o desconhecido são marcas constantes e abrem novas possibilidades, expectativas e perplexidades, estabelecendo um rompimento com elementos estabelecidos e vigentes, tanto no que se refere à ciência quanto ao que diz respeito à sociedade. Barbosa (2004, p. viii-xi) esclarece que esse “[...] cenário pós-moderno é essencialmente cibernético-informático e informacional [...]” e, nessa condição pós-moderna, são os saberes científico e técnico que produzem riqueza. Essa conjuntura e essa condição colocam as universidades em posição destacada, por conta do papel e da importância dessas instituições na sociedade.

No caso das universidades, a crise paradigmática fica evidenciada quando se compreende justamente essas instituições como geradoras de conhecimento científico e inovações ou formadoras de uma população mais educada, tais fatores essenciais ao desenvolvimento de um país. Os pilares que até então sustentaram esses processos baseados na razão, na lógica e na previsibilidade tornaram-se frágeis. A especialização e a fragmentação do conhecimento levaram a uma compreensão cada vez mais detalhada e profunda dos fenômenos, contudo isolada, o que tem impossibilitado a criação de uma visão de conjunto e uma compreensão abrangente de mundo. Almeida (2012, p. 36) explica que:

[...] assumir uma atitude dialogal diante dos fenômenos e não uma postura estritamente analítica de dissecação do cadáver configura uma das tendências da ciência; aceitar o paradoxo, a incerteza e o inacabamento como propriedades dos fenômenos e do sujeitoobservador, uma sugestão desafiadora; admitir que o erro parasita o ato de conhecer; que é tênue o limite entre realidade, ilusão e ficção, e que as interpretações e teorias são sempre mais, ou menos, do que os fenômenos aos quais se referem, configura hoje um estilo cognitivo em elaboração.

No Brasil, as universidades ${ }^{1}$, apesar de instituídas tardiamente no território brasileiro, consolidaram-se ao longo de sua trajetória como locus da produção científica nacional e formação de recursos humanos especializados. As atividades nessas instituições também se transformam em resposta às alterações na pesquisa e na transmissão do conhecimento em decorrência das tecnologias, à legitimação pelo desempenho e ao reconhecimento do conhecimento como força econômica de produção (LYOTARD, 2004). 
As universidades federais brasileiras assumem, como escopo de sua atuação, o ensino, a pesquisa e a extensão. Para dar conta dessas atividades, elas dispõem de bibliotecas como parte importante de uma infraestrutura e de um sistema de comunicação científica maior. As bibliotecas, em geral, também passam por um momento de desafios, procuram encontrar equilíbrio entre as técnicas tradicionais de organização e as voltadas para novas tecnologias, entre fornecer informação em papel e fornecer informação digital, entre disponibilizar a informação e propiciar o acesso à informação. Enfim, como registra Castro (2006), significa ter que "[...] navegar pelo novo sem renegar ou relegar ao esquecimento as marcas do passado." (CASTRO, 2006, p. 1).

Este artigo tem por objetivo refletir sobre o papel das bibliotecas universitárias nesse cenário denominado de pós-modernidade. Para tanto, as características desse período serão apresentadas, assim como os desafios educacionais decorrentes. Com a finalidade de contextualização discorre-se sobre as bibliotecas e seus significados na sociedade e sobre o papel dessas na história da humanidade e, em especial, o papel das bibliotecas universitárias na contemporaneidade.

\section{A sociedade pós-moderna e os desafios educacionais}

No final do século XX, muitos estudiosos chegaram à conclusão de que outra era despontava e levava a sociedade ao distanciamento da era da Modernidade, visto que tanto progresso e tanta racionalidade causaram o desencantamento com o mundo. Para denominar essa era, vários termos foram cunhados para caracterizar a transição. Alguns deles referiam-se à emergência de um novo tipo de sistema social (por exemplo, sociedade de informação e sociedade de consumo) e, considerando que esse período indicava um encerramento, mais do que um estado de coisas precedentes, muitos autores preferiram denominar esse período de pós-modernidade, pós-modernismo, sociedade pós-industrial, e assim por diante (GIDDENS, 1991). Na concepção da abordagem deste artigo, entendeu-se a sociedade contemporânea como uma sociedade pós-moderna, visto que o termo pós-modernidade acolhe nesse termo "todas as formas de 
mudança - cultural, política e econômica" da vida da humanidade (KUMAR, 1997, p. 15), consequentemente, incorporando elementos das outras designações. A pós-modernidade pode ser caracterizada como um movimento de reação aos ideais da Modernidade, em função da perda de otimismo e da confiança nesses ideais, e da descrença acerca de teorias, narrativas e ideologias que buscavam colocar o conhecimento em um único sistema.

A concepção de sociedade pós-moderna foi difundida amplamente na década de 70 do século XX, a partir da obra de Lyotard ${ }^{2}$ que abordou a situação do saber nas sociedades mais desenvolvidas. De tal maneira, ele tratou a pósmodernidade como uma mudança na condição humana (ANDERSON, 1999). O autor buscou situar o conhecimento científico na condição pós-moderna, utilizando tal denominação para designar “[...] o estado da cultura após as transformações que afetaram as regras dos jogos da ciência, da literatura e das artes a partir do final do século XIX.” (LYOTARD, 2004, p. Xv).

Para Lyotard (2004), na pós-modernidade, o conhecimento torna-se a principal força econômica de produção, ao mesmo tempo que perde as suas legitimações tradicionais. A pós-modernidade é marcada pela "incredulidade em relação aos metarrelatos", decorrência do reconhecimento da contradição dos jogos de linguagem, pois não há um discurso único e total que abarque todas as explicações e todo o conhecimento. Além disso, há uma mercantilização do saber, o conhecimento é transformado em mercadoria produzida e comercializada que confere poder àqueles que o produzem e o detêm (LYOTARD, 2004, p. xvi). Lyotard (2004), reconhecendo a insuficiência dos metarrelatos e do consenso como critério de validação do discurso científico pós-moderno, critica a legitimação pelo desempenho e apresenta um modelo de legitimação pela paralogia ${ }^{3}$, admitindo a imprevisibilidade, a contradição e a diferença.

Essa conjuntura tem gerado muitas incertezas e, nessa perspectiva, Jencks (1989, p. 7) explica que a era pós-moderna é um:

[...] tempo de opção incessante. É uma era em que nenhuma ortodoxia pode ser adotada sem constrangimento e ironia, porque todas as tradições aparentemente têm alguma validade. Esse fato é 
em parte consequência do que se denomina de explosão de informações, do advento do conhecimento organizado, das comunicações mundiais e da cibernética. [...] O pluralismo, o "ismo" de nossa época, é, ao mesmo tempo, o grande problema e a grande oportunidade $[\ldots]$.

Assim, a sociedade contemporânea é marcada pelo fim dos padrões, da estabilidade, da segurança e das certezas. Vive-se no tempo da indefinição, do medo e da insegurança (BAUMAN, 2001). A vida na pós-modernidade abandona os tipos tradicionais de ordem social, rompe com a ideia de verdade. O saber é permeado pela dúvida, pela suspeita e pela falta de verdades absolutas.

Muitos pensadores da pós-modernidade estão fascinados, segundo Harvey (1993, p. 53), pelas “possibilidades da informação, da produção, análise e transferência de conhecimentos". Para Lyotard (2004), por exemplo, as tecnologias que proporcionam a produção, a disseminação e o uso do conhecimento são destacadas como uma importante força de produção e, em decorrência, esse autor reconhece que parte das mudanças da sociedade contemporânea advém de mudanças nas condições técnicas. O saber mudou de estatuto quando as sociedades entraram na idade dita pós-industrial e as culturas na idade dita pós-moderna, o que ocorreu no século XX. A incidência das informações tecnológicas sobre o saber afetou a pesquisa e a transmissão de conhecimento (LYOTARD, 2004). As transformações culturais e o impacto das tecnologias levaram às modificações nos estatutos da ciência e da universidade, impulsionadas pelo impacto das transformações tecnológicas (BARBOSA, 2004), pois as máquinas informacionais afetam e afetarão “[...] a circulação dos conhecimentos, do mesmo modo que o desenvolvimento dos meios de circulação dos homens (transporte), dos sons e, em seguida, das imagens (media) o fez." (LYOTARD, 2004, p. 4).

No ensino superior, como argumenta Lyotard, "O essencial do transmissível é constituído por um estoque organizado de conhecimentos." (LYOTARD, 2004, p. 91). Logo, as novas técnicas aplicadas a esse estoque poderão ter "incidência considerável sobre o suporte comunicacional", considerando-se que: 
[...] os conhecimentos são traduzíveis em linguagem informática, e enquanto o professor tradicional é assimilável a uma memória, a didática pode ser confiada à máquinas articulando as memórias clássicas (bibliotecas, etc.) bem como os bancos de dados e terminais inteligentes colocados à disposição dos estudantes. (LYOTARD, 2004, p. 92).

Nestes tempos, a vida das pessoas e, principalmente, a forma como as pessoas aprendem foram transformadas. Segundo Pourtois e Desmet (1999) trata-se de uma nova realidade em que o universo social, cultural e pedagógico para ser coerente e integrador tem que ser capaz de acolher ao mesmo tempo a razão e o ser, a racionalização e a subjetivação. Ainda, requer que se leve em conta o caráter instável do conhecimento e que a convivência com as incertezas seja regra. Tudo fica na dependência da mediação entre fatos contraditórios, e as descobertas são realizadas via integração e articulação de saberes. O sistema de pensamento almejado é o sustentado pela integração e pela complexidade.

A aprendizagem tem ultrapassado o ambiente educacional e ocorre em diversos contextos, inclusive na Internet. Com base nessa ideia, Beillerot (1985) usou a expressão sociedade pedagógica para designar esse fenômeno, considerando a interface educativa presente nas dinâmicas das relações sociais do mundo contemporâneo. Para Beillerot (1985), nessa sociedade pedagógica, os espaços pedagógicos foram ampliados, e existem instâncias privadas ou públicas que estão empenhadas em fazer pedagogia. Ao lado das instâncias tradicionais, como as escolas e as famílias e, diante da necessidade de formar os indivíduos para toda a vida, outras instituições têm acentuado seu papel nesse processo, como, por exemplo, as empresas, os sindicatos, as associações de classe e, por certo, as bibliotecas, os museus e as mediatecas. A ação pedagógica está no centro de um complexo desenvolvimento social e tecnológico, no qual as relações sociais assumem formas de relações pedagógicas.

O pressuposto básico da educação pós-moderna é preparar para a autonomia, para desenvolver a capacidade de cada cidadão autogovernar-se (GADOTTI, 1993). A educação pós-moderna leva em conta a diversidade cultural (GADOTTI, 1993, p. 311), significando “[...] uma educação para todos que respeite a diversidade, as minorias étnicas, a pluralidade de doutrinas, os 
direitos humanos, retirando os estereótipos, ampliando o horizonte de conhecimento e de visões de mundo [...]" (GADOTTI, 1993, p. 311). O conhecimento tem um caráter prospectivo e "[...] a educação trabalha mais o significado do que o conteúdo, muito mais a intersubjetividade e a pluralidade do que com a igualdade e a unidade." (GADOTTI, 1993, p. 312).

Segundo Bernheim e Chauí (2008), diante dos desafios da educação superior para equilibrar as funções básicas de ensino, pesquisa e extensão 0 modelo estrutural perfeito capaz de apoiar todas as complexas funções das universidades ainda está para ser construído. O ideal seria que os modelos atuais, baseados em estruturas rígidas (cátedras, faculdades, escolas, departamentos e institutos), fossem substituídos por modelos mais flexíveis que promovam a reintegração do conhecimento, o estabelecimento da interdisciplinaridade e a recuperação da concepção integral da universidade.

Outra questão, para as premissas básicas da educação, e que acresce uma dimensão diferente ao desafio acima citado, está relacionada à "natureza errática e essencialmente imprevisível da mudança contemporânea" (BAUMAN, 2002, p. 49). O conhecimento sempre foi valorizado por sua fiel representação do mundo, devido à "ordem imutável do mundo", justificando a necessidade e os benefícios da transmissão do conhecimento, e a "natureza similarmente eterna das leis que governam a natureza humana", dando ao professor a autoconfiança necessária para gravar na personalidade dos alunos como o escultor no mármore. Tais conjeturas são difíceis de sustentar na atualidade, afinal neste "mundo volátil [...] dificilmente alguma coisa preserva sua forma o tempo necessário para garantir a verdade e gelatinizar-se em algo confiável por muito tempo [...]" (BAUMAN, 2002, p. 50). Em decorrência, “[...] os hábitos arraigados, as estruturas cognitivas sólidas e a preferência por valores estáveis, objetivos últimos da educação ortodoxa, transformaram-se em desvantagens." (BAUMAN, 2002, p. 51).

Na pós-modernidade, os desafios educacionais, segundo Pereira (2000), “[...] estão em preparar os indivíduos para a transitoriedade de todos os aspectos da vida, trazendo a necessidade da atualização constante e da emancipação 
como sujeitos históricos.” (PEREIRA, 2000, p. 178). E, ainda, para “[...] compreender a atualidade de uma sociedade cada vez mais informacional e globalizada e perscrutar as direções futuras, dialogando com uma realidade cada vez mais carregada de símbolos.” (PEREIRA, 2000, p. 178).

Para o ensino assegurar o aumento das competências do sujeito, a transmissão do saber não poderá restringir-se somente à transmissão da informação, mas deverá comportar " [...] a aprendizagem de todos os procedimentos capazes de melhorar a capacidade de conectar campos que a organização tradicional dos saberes isola ciosamente." (LYOTARD, 2004, p. 94). Na pós-modernidade, o desafio para os processos educacionais das universidades é deixar de ser apenas uma etapa de preparação para a carreira profissional, transformando-os em processo permanente que durará toda a vida, e isso será possível "em interação com sistemas de conhecimento e redes informação" (SANTOS; ALMEIDA FILHO, 2012, p.137).

$\mathrm{Na}$ lista das questões enfrentadas pelas universidades ainda se destacam: atender a um número crescente de matrículas; equilibrar as funções básicas de ensino, desenvolver pesquisa e oferecer serviços; melhorar a administração da educação preocupando-se com o planejamento estratégico; lidar com a cultura informática tendo a tecnologia como um recurso auxiliar e não como substituta do professor; gerar conhecimento; estabelecer relações entre a educação superior e o mundo do trabalho, de modo a atender as necessidades de todos os setores da sociedade e formar profissionais para o mercado de trabalho e para a atuação na sociedade em suas diferentes esferas (BERNHEIM; CHAUÍ, 2008). É fundamental que tais instituições busquem formas de ensino para inserir os indivíduos na sociedade de maneira crítica e criativa e para iniciar o indivíduo no rito de aprendizagem ao longo da vida.

O ensino superior é um dos fomentadores da educação ao longo da vida. É tanto depositário como criador do conhecimento. É o principal instrumento de transmissão da experiência cultural e científica acumulada pela humanidade (DELORS et al., 1998). Cruz (2006, p. 42) lembra que a universidade é o local do conhecimento, “[...] é o lugar que a sociedade constituiu, há séculos, para 
trabalhar com o conhecimento da maneira mais específica [...]”. Embora não seja o único lugar na sociedade em que se trabalhe com o conhecimento, a universidade é especial, por ser a instituição na qual " [...] existe um cuidado permanente para disseminar o trabalho com o conhecimento por toda a sociedade [...]". Logo, tem sua força "[...] na capacidade de gerar um tipo especial de conhecimento, na habilidade em trabalhar com ele e, principalmente, na competência em formar e educar pessoas para continuarem a executar ambas as tarefas [...]" (CRUZ, 2006, p. 42). Formar cidadãos para uma sociedade aberta e democrática postula:

[...] dotá-los de capacidades de aprendizagem, de modos de pensamento que lhes permitam utilizar estrategicamente a informação que recebem, para que possam converter essa informação - que flui de maneira caótica em muitos espaços sociais - em conhecimento verdadeiro, em um saber ordenado. (POZO, 2004, p. 1).

No que tange às competências básicas para o aprendizado contemporâneo, observa-se que são essenciais: capacidade reflexiva e crítica; capacidade de solução de problemas; capacidade de adaptação a novas situações; capacidade de selecionar a informação relevante nas áreas de trabalho, cultura e exercício da cidadania que permita tomar decisões corretas; capacidade de continuar aprendendo em contextos de mudança tecnológica e sociocultural acelerada, com a permanente expansão do conhecimento; capacidade para buscar espaços intermediários de conexão entre os conteúdos das várias disciplinas, de modo a realizar projetos que envolvam a aplicação de conhecimentos ou procedimentos próprios de diversas matérias; capacidade de apreciar a leitura e a escrita, o exercício do pensamento e a atividade intelectual, de modo geral (BERNHEIM; CHAUÍ, 2008).

Como visto, a sociedade contemporânea é marcada por alguns dilemas e desafios. É indispensável que as instituições como universidades e suas bibliotecas reinventem seus caminhos para enfrentar os desafios desta era. Para Santos (1994), vivem-se inúmeros dilemas na pós-modernidade que geram perplexidades, angústias e desconfortos. Contudo, eles não devem levar ao 
desalento, devem ser vistos como desafios à imaginação, à criatividade e ao pensamento.

\section{As bibliotecas e seus significados na sociedade}

A biblioteca, instituição secular do conhecimento e da memória, tradicionalmente coleciona, preserva e dissemina os saberes produzidos pela sociedade. Nas coleções de uma biblioteca é preservado "[...] o conjunto dos elementos históricos que informam os sujeitos sobre seu passado, e que esses the conferem a possibilidade de projetar uma explicação para o presente, de divagar acerca do futuro [...]" (SILVEIRA, 2010, p. 83).

Para iniciar a explanação sobre os significados das bibliotecas na sociedade, revela-se que a palavra biblioteca em grego é formada por dois étimos: biblio-teca. Biblio era o nome que os gregos davam à entrecasca de um arbusto, uma espécie de cipreste, conforme explica Leão (2000). Antes de significar livro significava entrecasca, pois dessa entrecasca era fabricado o papiro. O radical transmite a ideia básica de colher e recolher, para acolher e escolher. As funções do livro estão ligadas aos três verbos, recolher, acolher e escolher, todos derivados de colher. O étimo teca refere-se a estabelecer e instituir, no sentido de guardar e cuidar, de promover e expandir. A palavra biblioteca, para integrar todos esses sentidos, deve indicar um lugar que seja instaurador de vitalidade, um lugar que não apenas guarde e proteja os documentos, "[...] mas, sobretudo, que acione todas as suas potencialidades de gerar transformações, de induzir mudanças de estrutura.” (LEÃO, 2000, p. 9).

O termo biblioteca também pode designar "[...] o compartimento para um livro, o lugar de depósito dos livros, o lugar onde se põem, depositam, deixam repousar, o lugar onde se guardam em depósito ou armazenam os livros [...]" (DERRIDA, 2004, p. 21), por outro lado pode nomear o lugar que coloca materiais informacionais de diferentes formatos "à disposição dos usuários", tornando-se "um espaço de trabalho, de leitura e de escrita" (DERRIDA, 2004, p. 22). Pensar a biblioteca e sua coleção é também pensar na tensão entre "reunir e dispersar" (CHARTIER, 1999, p.115), entre inércia e movimento (DERRIDA, 2004). As bibliotecas, como instituição, resultam do: 
[...] cruzamento paradoxal de um projeto utópico (fazer coexistir num mesmo espaço todos os vestígios do pensamento humano confiados à escrita) com as restrições técnicas, ergonômicas, políticas de conservação, de seleção, de classificação e de comunicação dos textos, das imagens e, hoje, dos sons. É também, e simultaneamente, um desígnio intelectual, um projeto, um conceito imaterial que dá sentido e profundidade às práticas de leitura, de escrita e de interpretação. (JACOB, 2008a, p. 10).

Consciente de que o acúmulo de conhecimentos permite ao homem reviver outras épocas e tradições, as bibliotecas são instrumentos da luta contra a severidade do tempo, uma vez que possibilitam trazer fragmentos do passado para o presente e, ainda, espelhar a identidade de uma sociedade ou de uma nação (MANGUEL, 2006). Sendo assim, proporcionam “[...] aos leitores uma visão de relance, mesmo que secreta ou distante, das mentes de outros seres humanos, e permite que tenham, por meio das histórias conservadas para seu escrutínio, um certo conhecimento de sua própria condição.” (MANGUEL, 2006, p. 35).

As bibliotecas são espaços de memória, suas coleções armazenam a história da humanidade (JACOB, 2008a). Como uma imensa base de dados, a biblioteca presta-se "à descontextualização dos enunciados e dos fragmentos, à sua circulação e às suas permutas” (JACOB, 2008b, p. 64). Segundo Nora (1993), as informações que eram memorizadas e transmitidas de pessoa a pessoa passaram a ser armazenadas, quando inscritas em suportes. Com o desaparecimento da memória tradicional tende-se a acumular vestígios, testemunhos, documentos, imagens, discursos, sinais visíveis dos acontecimentos. As bibliotecas, os arquivos e os museus são em tese os lugares de memória. Lugares de memória surgem do sentimento de que não há mais memória espontânea, de que é preciso criar espaços para guardá-la, lugares nos quais a “[...] memória se refugia e se cristaliza." (NORA, 1993, p.9).

A memória, seja nossa memória individual ou a memória coletiva que é a cultura, tem a dupla função de conservar certos dados e de relegar ao esquecimento as informações que no momento não são úteis. Assim, 
as bibliotecas são esses frigoríficos nos quais armazenamos a memória a fim de que o espaço cultural não fique abarrotado com toda essa quinquilharia, mas sem isso renunciar a ela. Poderemos sempre, no futuro, se o coração nos ditar, voltar a eles. (ECO, 2010, p. 59-60).

Bibliotecas são lugares nos quais se estabelece o equilíbrio entre a memória e o esquecimento, entre o que deve ser lembrado/guardado e o que deve ser esquecido/descartado (JACOB, 2008). Nora (1993) ressalta que os lugares de memória são necessários para permitir reconstituir a representação de um passado coletivo. Os lugares de memória surgem justamente para se criar memória que guarde vestígios, testemunhos, documentos, imagens, discursos, sinais visíveis do que foi (NORA, 1993).

As bibliotecas como lugares de memória possibilitam, segundo Silveira (2010, p. 69, grifo do autor), “[...] reafirmar os saberes e a torná-los móveis, traduzíveis, permutáveis, enfim, [...] dar sentido ao saber e a fazer com que o mesmo se torne um instrumento de reafirmação da identidade individual ou coletiva humana.”. São instituições que permitem, por meio de suas coleções, o acesso às " [...] experiências comuns a toda humanidade, bem como as razões e os intentos de cada um de seus usuários em particular." (SILVEIRA, 2010, p. 79). Isto posto, “[...] o lugar de memória é um lugar duplo; um lugar de excesso, fechado sobre si mesmo, fechado sobre sua identidade, e recolhido sobre seu nome, mas constantemente aberto sobre a extensão de suas significações." (NORA, 1993, p. 27).

Latour (2006) explica que a biblioteca também não é uma fortaleza isolada, mas um nó em uma vasta rede na qual circulam matérias que se tornam signos. Além disso:

[...] não se ergue como o palácio dos ventos, isolado numa paisagem real, excessivamente real, que lhe serviria de moldura. Ela curva o espaço e o tempo ao redor de si, e serve de receptáculo provisório, de dispatcher, de transformador e de agulha a fluxos bem concretos que ela movimenta continuamente. (LATOUR, 2006, p. 21).

A conexão da biblioteca com o mundo exterior é realizada via registros de informação. A informação, segundo Latour (2006, p. 22), “[...] não é um signo, e sim uma relação estabelecida entre dois lugares, o primeiro que se torna 
uma periferia e o segundo, que se torna um centro [...]", e entre os dois circula um veículo que o autor denomina de inscrição. É necessário ligar os signos ao mundo, meditar sobre as relações entre as inscrições e os fenômenos, os signos não remetem a si próprios. A coleção de uma biblioteca não está ligada somente entre si pelas citações realizadas entre as obras, está ligada ao mundo exterior pela captura e registro do conhecimento. Latour (2006, p. 26) explica que a biblioteca liga-se a outros lugares via conéctica, "[...] cada dado se liga, por um lado, a seu próprio mundo de fenômenos e, por outro lado, a todos aqueles com os quais se torna compatível.” (LATOUR, 2006, p. 31).

Nessa visão, a biblioteca pode ser infinita como a Biblioteca de Babel que se multiplica como em um jogo de espelhos, “[...] compõe-se de um número indefinido, e talvez infinito, de galerias hexagonais [...] [e] de qualquer hexágono, avista-se os andares inferiores e superiores: interminavelmente." (BORGES, 1999, p. 38). Então, “[...] a biblioteca é tão imensa que toda redução de origem humana resulta infinitesimal." (BORGES, 1999, p. 41).

Burke (2012, p. 141, grifo do autor), evocando Michel Foucault, que costumava reafirmar que saber é poder, e o conceito de reciclagem (reemprego) do conhecimento de Certeau, argumenta que "[...] as inovações intelectuais, como as tecnológicas, são em sua maioria adaptações criativas de ideias ou artefatos anteriores, e assim a chamada originalidade é mais relativa do que absoluta.”. Dito isso, segundo esse autor, para que se possa "empregar o conhecimento ou agir com base nele" (BURKE, 2012, p.1 41), é preciso que existam lugares, tais como as bibliotecas, nos quais esse conhecimento possa ser recuperado.

As ideias expostas acima revelam alguns dos significados e das percepções possíveis sobre as bibliotecas que expõem indícios da importância dessas instituições na sociedade.

\section{As bibliotecas na história da humanidade e os desafios da pós-} modernidade

As bibliotecas sugiram em decorrência da escrita e da leitura (MARTINS, 2002; FISCHER, 2006) e foram compostas por diferentes materiais utilizados pelo 
homem para registrar o conhecimento: os livros gravados em argila na Mesopotâmia, os rolos de papiro em Alexandria, os pergaminhos em Pérgamo, as ripas de madeira ou bambu na China, as peles de veado e as fibras de agave utilizadas pelos Astecas na América e os códices utilizados na era cristã em Roma (BATTLES, 2003).

No final do segundo milênio a. C., formavam as bibliotecas, materiais tais como: tabuletas de argila, papiro, placas de madeira, varetas de bambu, seda ou couro, verdadeiros depósitos de informação que devido a sua importância para a administração das cidades-estados concediam poderes às sociedades da região da Mesopotâmia (FISCHER, 2006). As bibliotecas primitivas de Cnossos, Festos, Micenas, Atenas e outros locais também cumpriam apenas as exigências imediatas de arquivamento.

Até o final da Idade Média, as bibliotecas tinham como função acumular os registros do conhecimento existentes e, em muitos casos, visavam atender aos interesses da realeza (MARTINS, 2002). A biblioteca de Alexandria é um exemplo, “[...] foi um centro de estudos fundado pelos reis ptolemaicos no fim do século III a. C. para melhor preservar os ensinamentos de Aristóteles." (MANGUEL, 2006, p. 27). Tinha como objetivo “[...] englobar a totalidade do conhecimento humano [...]" (FISCHER, 2006, p. 54). A organização dos rolos de papiro por tema, realizada na biblioteca de Alexandria, inicia a transformação da concepção da biblioteca de depósito de rolos de papiro para a de um centro de informações sistematizadas, na época era considerada o principal centro de aprendizado do Mediterrâneo (FISCHER, 2006).

As tabuletas de argila e as folhas de papiro atenderam as necessidades dos leitores por milhares de anos, até que os gregos orientais, para criar um novo material para a escrita e para a biblioteca de Pérgamo, aprimoraram uma técnica de estiramento de pele de ovelhas e cabritos e desenvolveram o pergaminho (FISCHER, 2006). O códice, páginas escritas em ambos os lados para que fossem viradas, foi criado por Júlio César, ao dobrar uma folha de papiro para enviar às suas tropas no campo de batalha (FISCHER, 2006).

Na Idade Média, as bibliotecas estavam sob a tutela da Igreja, e o acesso aos conteúdos dos pergaminhos e códices era restrito aos que optavam pela 
formação na universitas, instituições ligadas à Igreja e precursoras da universidade e das bibliotecas universitárias. Nesse período, as bibliotecas eram uma extensão das ordens eclesiásticas (MARTINS, 2002), destinadas à conservação do saber e entendidas como uma entidade privada. A biblioteca mais antiga do cristianismo armazenava vários livros da Bíblia, comentários bíblicos, obras de apologistas gregos e um conjunto de clássicos gregos e latinos (FISCHER, 2006). As bibliotecas monásticas foram os locais nos quais o conhecimento permaneceu guardado, alguns textos eram considerados sagrados e o acesso era restrito a poucos (ANZOLIN; CORREA, 2008).

O início do processo de socialização, especialização, democratização e laicização da cultura contribuiu para as coleções tornarem-se mais acessíveis e, também, possibilitou a inclusão de obras científicas e filosóficas, contribuindo para a constituição das primeiras coleções de bibliotecas universitárias. As bibliotecas passaram a desempenhar um papel essencial na vida das comunidades modernas, de modo que ao seu redor circulam os fluxos da existência social (MARTINS, 2002).

As primeiras tentativas de constituição de bibliotecas universitárias foram realizadas ao longo dos séculos XIII e XIV, conforme Battles (2003). Ainda na Idade Média, no século XIV, os estudiosos tentavam extrair o máximo de significado de um texto. Nas universidades, os textos copiados por copistas profissionais com credibilidade garantida eram poucos, devido ao preço (FISCHER, 2006). No século XV, a invenção de Gutemberg, uma prensa para reprodução em massa de páginas de papel impressas, possibilitou "a oferta ao público de cópias quase infinitas de textos idênticos", assim, "[...] transformou uma sociedade cujo acesso ao conhecimento era limitado em outra cujo acesso era quase ilimitado.” (FISCHER, 2006, p. 196).

Em função da maior facilidade de acesso aos livros, no século XVII, “[...] as bibliotecas das universidades e das escolas públicas multiplicaram o número de volumes [...]" (FISCHER, 2006, p. 214) em suas coleções. No entanto, até a primeira metade do século XVII, eram valorizados os aspectos religiosos ou relativos à raridade e luxo das obras em vez do valor do conteúdo. 
Gabriel Naudé, no século XVII, defendeu a ideia de biblioteca aberta para todos em seu livro Advis pour dresser une bibliotèque ou Conselhos para organizar uma biblioteca, no qual abordou todos os aspectos da biblioteca e, também, destacou que para iniciar uma biblioteca é preciso ler e consultar grandes colecionadores de livros. A biblioteca ideal para Naudé era aquela em que todos os assuntos e pontos de vista estão representados. Assim, ela deve fornecer todos os principais autores, antigos e modernos, obscuros ou conhecidos, religiosos ou seculares, nas melhores edições. Em especial, deve dar atenção aos assuntos polêmicos, e nenhum esforço poupado para ter presente na biblioteca os prós e contras desses. A biblioteca deve informar e encantar a todos (LEMKE, 1991).

Durante o século XVIII, reis, príncipes, condes e bispos em toda a Europa iniciaram a construção de enormes bibliotecas no estilo de mausoléus clássicos para abrigar as obras lidas por eles. Nesse período, surgiram as bibliotecas públicas, como a Biblioteca do Museu Britânico, inaugurada em virtude da aquisição de diversas coleções particulares do Parlamento. As bibliotecas e cafés iniciaram o costume de alugar livros mediante o pagamento de uma taxa (FISCHER, 2006).

A partir do século XIX, com a expansão do volume da produção editorial, a abordagem acumulativa e exaustiva em relação às coleções cedeu lugar à necessidade de selecionar as obras de relevância e de qualidade. No século XX, o grande volume de produção editorial, a especialização das áreas do conhecimento e os grandes investimentos em pesquisa agravaram a situação e culminaram em procedimentos mais avançados para lidar com a complexidade das coleções em bibliotecas (WEITZEL, 2012).

A concepção da biblioteca como instituição social também foi destacada por Ranganathan no século XX. O autor criou As cinco leis da Biblioteconomia e abordou questões pertinentes à gestão das bibliotecas e suas coleções e defendeu que a biblioteca deve possibilitar o acesso universal ao conhecimento (RANGANATHAN, 2009). As leis propagadas por esse autor indicam a constituição de uma biblioteca dinâmica que promove e divulga as coleções; oferece acesso ao conhecimento e engloba a variedade de suportes e formatos 
em que a informação apresenta-se; está atenta aos interesses dos usuários e considera suas preferências e hábitos de uso da informação. Em conformidade, a biblioteca estará em crescimento, acompanhando as transformações tecnológicas e as mudanças nos registros do conhecimento, analisando as necessidades dos usuários, buscando a atualização de sua coleção e novas formas para possibilitar o acesso ao conhecimento como instrumento para a educação.

No século XX, as concepções indicavam que, para manter as bibliotecas como organismos vivos e atuantes, deveriam mudar a ênfase da acumulação do material para acesso ao mesmo, de forma que o limite para uso das coleções seria o próprio limite do conhecimento recuperável e que as bibliotecas contemplassem todas as fontes de informação (VERGUEIRO, 1989). Em decorrência do crescimento exponencial das publicações, ocorrida após a Segunda Guerra Mundial, há um aumento na preocupação com o planejamento das coleções. Assim, a partir da década de 60, o foco voltou-se ao desenvolvimento de coleções, com ênfase na seleção (JOHNSON, 2014), buscando desenvolver, selecionar, expurgar e transformar as coleções em algo atraente (VERGUEIRO, 1989), em resposta às prioridades institucionais e às necessidades e interesses da comunidade usuária (JOHNSON, 2014).

No século XXI, as bibliotecas, ao mesmo tempo em que lidam com a diversidade dos suportes de informação disponíveis e diversificam serviços e produtos, também enfrentam restrições orçamentárias que limitam o processo de formação e desenvolvimento de coleções. Por essas razões, é imprescindível optar pela flexibilidade, adaptabilidade, interdependência e cooperação (ANZOLIN; CORRÊA, 2008).

As bibliotecas virtuais e/ou digitais surgem como uma nova configuração de bibliotecas (ANZOLIN; CORRÊA, 2008). Implantadas em congruência com as transformações na sociedade, buscam incorporar os recursos tecnológicos às suas atividades e às suas coleções, sem deixar de se preocupar com a reunião, armazenamento, organização e disponibilização da informação, para suprir a busca de informações em todas as esferas da sociedade. 
A preocupação com a preservação de materiais digitais está em consonância com a importância da preservação das coleções, que, de acordo com a Unesco (ORGANIZAÇÃO DAS NAÇÕES UNIDAS PARA A EDUCAÇÃO, A CIÊNCIA E A CULTURA, 1999), representam uma parte da herança nacional e universal.

As bibliotecas universitárias, diante do crescente volume de fontes de informação e sua diversidade de suportes e formatos, empenham-se para desenvolver ações para constituir uma malha rizomática, conectada a outros pontos que viabilizem o acesso, na qual transite o estoque de conhecimento necessário ao processo ensino-aprendizagem, à pesquisa e às atividades de extensão, sem rejeitar as formas tradicionais consolidadas, visto que é preparando-se para as mudanças que as bibliotecas demonstram sua perenidade (CARVALHO, 2004).

Nesta nova era, é fundamental que as bibliotecas universitárias amplifiquem a sua atuação, participem dos processos educacionais, transformem-se em lugares para a aprendizagem, valorizando a comunicação e a troca de informação. A Unesco, em 1999, ao propor uma política de mudança para o ensino superior, enalteceu o papel da biblioteca, denominando-a de "[...] centro nervoso para a interação entre aqueles que providenciam as informações e seus usuários [...]", ressaltando que arquivos, museus e bibliotecas “[...] providenciam não somente um local físico, mas também um contexto intelectual para a guarda, preservação e troca de conhecimento." (ORGANIZAÇÃO DAS NAÇÕES UNIDAS PARA A EDUCAÇÃO, A CIÊNCIA E A CULTURA, 1999, p. 73).

Historicamente, as bibliotecas dedicaram-se à formação de coleções, acompanhando a evolução dos registros do conhecimento e as transformações pelas quais as sociedades passaram. $\mathrm{Na}$ Antiguidade, elas eram guardiãs do conhecimento da humanidade; na Idade Média, transformaram-se em centros de informação sistematizada; na Idade Moderna, com a invenção da imprensa, o acesso ao conhecimento torna-se quase ilimitado e a ideia de biblioteca aberta a todos foi difundida. No ambiente da pós-modernidade, as bibliotecas enfrentam novos delineamentos e seus administradores fazem um esforço para reconhecer 
que o conhecimento não existe separado da elaboração humana, é criado por seres humanos em busca de significado, e embalado em narrativas locais que variam de grupo para grupo. É imprescindível que as bibliotecas demonstrem que desempenham um papel crucial na vida da universidade (YODER, 2003). Ainda, é oportuno fornecer informação aos usuários, mas agora se tornou necessário capacitá-los para encontrar e avaliar as informações armazenadas em seus próprios equipamentos, já que a ideia de aprendiz, ao longo da vida, e o uso de tecnologias de informação e comunicação têm afetado a biblioteca em relação ao acesso à informação e ao papel do bibliotecário quanto aos usuários e à organização da informação (ROBERTSON, 2013).

Quanto ao futuro das bibliotecas, embora possam parecer instituições arcaicas, segundo Darnton (2010), o passado delas como centros de saber “[...] guarda bons presságios para seu futuro [...] [e] sua posição central no mundo do saber as torna ideais para mediar os modos impresso e digital de comunicação." (DARNTON, 2010, p. 16).

Para as bibliotecas universitárias, o desafio passa pela necessidade de considerar essa organização e seus processos do ponto de vista multidimensional. Antes de qualquer parâmetro, é preciso pontuar que o alinhamento da biblioteca à missão da universidade é indiscutível e que ela possa manter-se como uma instituição central na sociedade pós-moderna é um desafio a ser enfrentado, ao mesmo tempo em que se idealiza que busque condições para ter uma função proativa nos processos de aprendizagem e na formação de pessoas nessa instituição. Em decorrência, em primeiro lugar, quanto a essa organização, é vital considerá-la ao mesmo tempo um lugar de memória científica, um lugar de expansão do conhecimento e um lugar de apoio ao ensino, pesquisa e extensão desenvolvidos na universidade. Em segundo lugar, quanto à coleção, requer que se tenha em conta que uma boa coleção deve contemplar a pluralidade das correntes teóricas e abordagens existentes, o equilíbrio entre o velho (obras clássicas), o útil ${ }^{4}$ (obras dos planos de ensino) e o novo (pesquisa de ponta), a multiplicidade dos formatos da informação e de acesso à informação da atualidade e o atendimento às necessidades de informação dos usuários. 
Bibliotecas e coleções acompanham a história da humanidade e, como visto, transformaram-se juntamente com as sociedades.

\section{Considerações finais}

Os desafios colocados para as bibliotecas universitárias no cenário pós-moderno são muitos como, por exemplo, lidar com diferentes culturas (GADOTTI, 1993), afinal, todas as tradições têm alguma validade (JENCKS, 1989). Além de lidar com a aprendizagem em diferentes ambientes (BEILLEROT, 1985), com a ascensão do conhecimento para uso imediato, com a impossibilidade de consolidação de qualquer coisa por algum tempo, pois tudo é transitório e, assim, é evidente a necessidade de a educação e a aprendizagem ocorrerem ao longo da vida (BAUMAN, 2002). Bibliotecas no âmbito das universidades, diante desses desafios, deverão colocar a disposição de seus usuários um amplo horizonte de conhecimentos e visões de mundo, devem ser um elo entre o presente e a história da humanidade, e um trampolim para a aprendizagem e a elaboração de outros conhecimentos.

Esse desígnio, muitas vezes, pode ser abalado por ações, recorrentes nas bibliotecas, derivadas da preocupação com a "[...] enxurrada de novos títulos, que agrava o problema de espaço para novas aquisições." (BURKE, 2012, p. 190). Algumas bibliotecas optam por “[...] dar baixa nos livros, eufemismo recente que significa desfazer-se deles"; outras “[...] banem os livros menos úteis para porões ou depósitos fora do local, um semialojamento ou limbo intelectual, inacessível ao público, mas ainda não na lata do lixo.” (BURKE, 2012, p. 190, grifo do autor). Burke (2012, p.188) alerta que, embora o descarte possa ser "desejável ou mesmo necessário, pelo menos até certo ponto", não se pode "esquecer as perdas que acompanham os ganhos", o descarte, inclusive em razão de obsolescência do conhecimento, pode ser visto "como uma forma de destruição criativa".

Ainda de acordo com Darnton (2010, p. 11-12), na atualidade, as bibliotecas universitárias enfrentam outras questões que certamente serão expandidas por todo o futuro da difusão do saber, 
[...] como sustentar os custos exorbitantes dos periódicos, preservar textos 'nascidos digitais', defender o fair use de textos por estudantes e incluir websites e e-mail entre as fontes armazenadas para futuras pesquisas. [...] como continuar adquirindo livros impressos ao mesmo tempo que se avança na frente digital? como desenvolver um novo modelo de negócios que liberte os periódicos científicos da especulação comercial de editoras? como legitimar monografias eletrônicas aos olhos de conservadores convencidos de que um livro só pode existir em forma impressa?

Como consequência dessas colocações, as bibliotecas universitárias têm, também, o desafio de encontrar o equilíbrio no desenvolvimento de suas coleções, significando não só participar de redes de informação, assim como ter uma coleção local que incorpore materiais em diferentes formatos, preserve autores clássicos, cujas obras nunca terminaram "[...] de dizer aquilo que tinham para dizer [...]" (CALVINO, 1995, p. 11), ao lado de autores de obras de “conhecimentos úteis" (BURKE, 2012, p. 147), impregnados de atualidade e demanda.

As bibliotecas de instituições de ensino superior precisam subsidiar diversas funções nesse contexto. Além de atuar no necessário apoio ao ensino, à pesquisa e à extensão vigente nas universidades, devem atuar como centros de informação para o aprendizado autônomo e, também, como lugares de memória científica da humanidade.

\section{Referências}

ALMEIDA, M. C. de. Ciências da complexidade e educação: razão apaixonada e politização do pensamento. Natal: EDUFRN, 2012.

ANDERSON, P. As origens da pós-modernidade. Rio de Janeiro: Jorge Zahar Editor, 1999.

ANZOLIN, H. H.; CORRÊA, R. L. T. Biblioteca universitária como mediadora na produção de conhecimento. Revista Diálogo Educacional, Curitiba, v. 8, n. 25, p. 801-817, set./dez. 2008.

BARBOSA, W. V. Tempos pós-modernos. In: LYOTARD, J. F. A condição pós-moderna. 8. ed. Rio de Janeiro: J. Olympio, 2004. 
BATTLES, M. A conturbada história das bibliotecas. São Paulo: Planeta do Brasil, 2003.

BAUMAN, Z. Desafios educacionais da modernidade líquida. Tempo Brasileiro, Rio de Janeiro, n. 148, p. 41-58, jan./mar. 2002.

BAUMAN, Z. Modernidade líquida. Rio de Janeiro: Jorge Zahar, 2001.

BEILlEROT, J. A sociedade pedagógica. Porto: Rés, 1985.

BERNHEIM, C. T.; CHAUÍ, M. S. Desafios da universidade na sociedade do conhecimento: cinco anos depois da conferência mundial sobre educação superior. Brasília: UNESCO, 2008.

BORGES, J. L. A biblioteca de Babel. In: BORGES, J. L. Ficções. Rio de Janeiro: Globo, 1999.

BURKE, P. Uma história social do conhecimento II: da enciclopédia à wikipédia. Rio de Janeiro: Zahar, 2012.

CALVINO, I. Por que ler os clássicos. São Paulo: Companhia das Letras, 1995.

LEÃO, E. C. O livro da linguagem. Tempo Brasileiro, Rio de Janeiro, n.142, p.7-13, 2000.

CARVALHO, I. C. L. A socialização do conhecimento no espaço das bibliotecas universitárias. Rio de Janeiro: Interciência, 2004.

CASTRO, C. A. Biblioteca como lugar de memória e eco de conhecimento: um olhar sobre o Nome da Rosa. Revista Digital de Biblioteconomia e Ciência da Informação, Campinas, v. 4, n. esp., p.1-20, 2006.

CHARTIER, R. A aventura do livro: do leitor ao navegador. São Paulo: UNESP, 1999.

CONNOR, S. Cultura pós-moderna: introdução as teorias do contemporâneo. São Paulo: Loyola, 1993.

CRUZ, C. H. de B. Pesquisa e universidade. In: STEINER, J. E.; MALNIC, G. (Org.). Ensino superior: conceito e dinâmica. São Paulo: USP, 2006. p. 30-45.

DARNTON, R. A questão dos livros: passado, presente e futuro. São Paulo: Companhia das Letras, 2010.

DELORS, J. et al. Educação um tesouro a descobrir: relatório para a UNESCO da Comissão Internacional sobre educação para o século XXI. São Paulo: Cortez, 1998. 
DERRIDA, J. O livro por vir. In: DERRIDA, J. Papel-máquina. São Paulo: Estação Liberdade, 2004. p. 19-34.

ECO, U. Todos os livros que não lemos. In: ECO, U.; CARRIÈRE, J. C. Não contem com o fim do livro. Rio de Janeiro: Record, 2010.

FISCHER, S. R. História da leitura. São Paulo: Unesp, 2006.

GADOTTI, M. Conclusão: desafios da Educação pós-moderna. In: GADOTTI, M. Histórias das ideias pedagógicas. São Paulo: Ática, 1993.

GIDDENS, A. As consequências da modernidade. São Paulo: UNESP, 1991.

HARVEY, D. Condição pós-moderna: uma pesquisa sobre as origens da mudança cultural. São Paulo: Loyola, 1993.

JACOB, C. Prefácio. In: BARATIN, M.; JACOB, C. (Org.). O poder das bibliotecas: a memória dos livros no Ocidente. 3. ed. Rio de Janeiro: UFRJ, 2008a. p. 9-17.

JACOB, C. Ler para escrever: navegações alexandrinas. In: BARATIN, M.; JACOB, C. (Org.). O poder das bibliotecas: a memória dos livros no Ocidente. 3. ed. Rio de Janeiro: UFRJ, 2008b. p. 45-73.

JENCKS, C. What is post-modernism? 3. ed. London: Academy Editions, 1989.

JOHNSON, P. Fundamentals of collection development \& management. 3. ed. Chicago: ALA, 2014.

KUMAR, K. Da sociedade pós-industrial à pós-moderna: novas teorias sobre o mundo contemporâneo. Rio de Janeiro: Zahar, 1997.

LATOUR, B. Redes que a razão desconhece: laboratórios, bibliotecas, coleções. In: BARATIN, M.; JACOB, C. (Org.). O poder das bibliotecas: a memória dos livros no Ocidente. 2. ed. Rio de Janeiro: UFRJ, 2006. p. 21-44.

LEMKE, A. B. Gabriel Naude and the ideal library. Syracuse University Library Associates Courier, Syracuse, v. 26, n, 1, p. 27-44, Spring 1991.

LYOTARD, J. F. A condição pós-moderna. 8. ed. Rio de Janeiro: José Olympio, 2004.

MANGUEL, A. A biblioteca à noite. São Paulo: Companhia das Letras, 2006.

MARTINS, W. A palavra escrita: história do livro, da imprensa e da biblioteca. São Paulo: Ática, 2002. 
MENDONÇA, A. W. P. C. A universidade no Brasil. Revista Brasileira de Educação, Rio de Janeiro, n.14, p. 131-150, maio/ago. 2000.

NORA, P. Entre memória e história: a problemática dos lugares. Projeto História, São Paulo, v. 10, p. 7-28, dez. 1993.

ORGANIZAÇÃO DAS NAÇÕES UNIDAS PARA A EDUCAÇÃO, A CIÊNCIA E A CULTURA. Política de mudança e desenvolvimento do ensino superior. Rio de Janeiro: Garamond, 1999.

PEREIRA, E. M. A. Pós-modernidade: desafios à universidade. In: PEREIRA, E. M. A. et al. (Org.). Escola e universidade na pós-modernidade. Campinas: Mercado de Letras, 2000. p. 163-200.

POURTOIS, J. P.; DESMET, H. A educação pós-moderna. São Paulo: Loyola, 1999.

POZO, J. I. A sociedade da aprendizagem e o desafio de converter informação em conhecimento. Pátio: revista pedagógica, Porto Alegre, v. 8, n. 31, p. 8-11, ago./out. 2004.

RANGANATHAN, S. R. As cinco leis da biblioteconomia. Brasília: Briquet de Lemos, 2009.

ROBERTSON, T. D. The postmodern shift in library instruction. Faculty Publications, New York, paper 10, 2013.

SANTOS, B. S. Pela mão de Alice: o social e o político na pós-modernidade. São Paulo: Afrontamento, 1994.

SANTOS, F. S.; ALMEIDA FILHO, N. de. A quarta missão da universidade. Brasília: UNB, 2012.

SILVEIRA, F. J. N. Biblioteca, memória e identidade social. Perspectivas em Ciência da Informação, Belo Horizonte, v. 15, n. 3, p. 67-86, set./dez 2010.

VERGUEIRO, W. Desenvolvimento de coleções. São Paulo: Polis: APB, 1989.

WEITZEL, S. R. Desenvolvimento de coleções: origem dos fundamentos contemporâneos. TransInformação, Campinas, v. 24, n. 3, p. 179-190, set./dez., 2012.

YODER, A. R. The cyborg librarian as interface: interpreting postmodern discourse on knowledge construction, validation, and navigation within academic libraries. Portal: libraries and the academy, Baltimore, v. 3, n. 3, p. 381-392, Jul. 2003 


\title{
The university libraries and the post-modernity challenges
}

\begin{abstract}
This paper discuss about university libraries and the current challenges they are facing. It's objective is to look for the possible functions and roles of these institutions in the post modernity. It addresses the topic of postmodernity and the university libraries' educational challenges. It also shows the importance of libraries and their significance throughout the history of mankind. It points out that to meet the challenges presented by post-modernity, university libraries must adopt pluralist approaches related to the type and the age of the documents in their collections, offer learning support and research opportunities, as well as offer autonomous learning. Finally, libraries need to be a place that preserves the scientific memory of mankind.
\end{abstract}

Key-words: University libraries. Post-modernity. Scientific memory.

Recebido: $17 / 07 / 2017$

Aceito: 16/11/2017

1 "Não há dúvida de que, se considerarmos a universidade como uma instituição específica da civilização ocidental, na forma em que se constituiu historicamente no contexto europeu, essa instituição não foi, ao longo do período colonial, implantada em nossas terras. [...] A primeira instituição que assumiu, entre nós, de forma duradoura, essa denominação foi a Universidade do Rio de Janeiro, criada em 1920, pelo governo federal.” (MENDONÇA, 2000, p.132, 136).

2 A expressão pós-moderno foi cunhada pelo historiador AntonioToynbee, conforme Connor (1993, p. 57), mas passa a ser difundida nos moldes atuais a partir da primeira edição da obra A condição pós-moderna de Lyotard, publicada na França, em 1979.

${ }^{3}$ Paralogia "[...] é um lance de importância muitas vezes desconhecida de imediato, feito na pragmática dos saberes." (LYOTARD, 2004, p. 112). Assim, coloca ênfase no dissentimento, pois as pesquisas construídas sob um pardigma tendem à estabilização, e é preciso desarranjar a ordem da razão, é preciso uma desestabilização para que surjam novas regras para o jogo de linguagem científico e até um novo campo de pesquisa. (LYOTARD, 2004). Ou seja, o autor reconhece a importância de o conhecimento considerar anomalias e construir novos conceitos e campos científicos.

$4 \mathrm{Na}$ acepção de Burke (2012) seria o conhecimento usável. Considera-se neste texto conhecimentos úteis aqueles contidos em obras que dão sustentação aos planos de ensino nas universidades, por isso têm altos índices de uso e circulação nas bibliotecas universitárias. 